\title{
A importância da pedagogia nos processos inclusivos
}

\author{
Morgana Domênica Hattge* \\ Viviane Klaus**
}

\section{Resumo}

O presente artigo busca, inicialmente, problematizar os processos inclusivos que se estabelecem nos ambientes educativos, com o objetivo de compreender os sentidos que a inclusão escolar assume no cenário educacional e acadêmico contemporâneo. Ao analisar-se uma série de pesquisas, que têm como foco a produção do anormal, a partir dos diagnósticos e tratamentos clínicos e psicológicos, percebe-se um silenciamento da Pedagogia, que se submete ao saber clínico ou da área psi e acaba por não cumprir sua função na produção de práticas pedagógicas que atendam às necessidades específicas dos sujeitos. Assim, o diagnóstico clínico passa a ser visto como uma verdade absoluta sobre o sujeito, de modo que as intervenções, muitas vezes, são restritas à medicalização. Desse modo, é fundamental refletirmos sobre as relações que se estabelecem entre esses diferentes saberes e seus efeitos nos espaços educativos. Este artigo é um convite à reflexão sobre os desafios da Pedagogia na construção de processos mais inclusivos, na área educacional.

Palavras-chave: Pedagogia; Saber pedagógico; Processos inclusivos.

* Professora Doutora do Centro Universitário Univates, Lajeado, Rio Grande do Sul, Brasil.

** Professora Doutora no Mestrado Profissional em Gestão Educacional da Unisinos, Universidade do Vale do Rio dos Sinos (UNISINOS). São Leopoldo, Rio Grande do Sul, Brasil. 


\section{The importance of pedagogy in the inclusion processes}

\section{Abstract}

This paper initially attempts to problematize the inclusion processes established in education settings. The aim is to understand the meanings that the school inclusion has taken in the contemporary educational and academic scenario. By analyzing a number of researches that have focused on the production of the abnormal from clini$\mathrm{cal}$ and psychological diagnoses and treatments, it is possible to notice the silence of Pedagogy, which is subject to the clinical or psy knowledge and ends up not playing its role in the production of pedagogical practices that meet the subjects' specific needs. Thus, the clinical diagnosis is regarded as absolute truth about the subject, and the interventions are often limited to medicalization. Therefore, it is fundamental to reflect on the relationships established between these different knowledges and their effects on the education settings. This paper invites us to reflect on the Pedagogy challenges in the construction of more inclusive processes in the education area.

Keywords: Pedagogy; Pedagogical knowledge; Inclusion processes.

Partindo de um olhar mais amplo para o que conhecemos e chamamos de História da Educação, podemos dizer que as discussões que temos empreendido a cerca da Inclusão Escolar, são bastante recentes se considerarmos que a escola é uma instituição que começa a constituir-se no século XVI e que o conceito de Inclusão Escolar passa a fazer parte do rol das preocupações educacionais há menos de três décadas¹. Dessa forma, cabe questionar: que sentidos assume essa expressão no cenário educacional contemporâneo? Que práticas de inclusão têm se instituído no interior da escola e/ou em outros espaços educativos? Considerando essas perguntas, este artigo está dividido em quatro seções. Na primeira, procuramos situar o conceito de inclusão no cenário atual e problematizar os processos inclusivos que se estabelecem nos ambientes educativos, em especial na escola. Na segunda seção, apresentamos algumas pesquisas a respeito do tema que nos desafiam a pensar sobre o quanto a Pedagogia tem sido silenciada nos processos inclusivos na escola. Na seção seguinte, procuramos mostrar a relação entre os saberes da educação, saúde e Pedagogia e os conhecimentos da área psi na produção dos sujeitos ditos e considerados anormais a partir de uma norma previamente estabelecida. Por fim, buscamos refletir sobre importantes desafios que se colocam à Pedagogia na construção de processos mais inclusivos na área educacional.

\section{Inclusão na escola: tensões permanentes}

Sabemos que as palavras não encerram em si seus significados. Os entendimentos que construímos acerca das "coisas" do mundo, sejam elas objetos, pessoas, lugares ou sentimentos, estão carregados das nossas concepções culturais, nossos 
princípios, crenças e experiências vividas. Não poderia ser diferente, no que diz respeito à Inclusão Escolar. Muitas são as opiniões, muitos são os entendimentos, e, a partir deles, muitas serão também as práticas desenvolvidas. A produção acadêmica sobre o tema pode dar uma mostra dessa diversidade.

Importa dizer que não pretendemos realizar, neste artigo, uma revisão bibliográfica, nem mostrar o estado da arte sobre a temática que estamos discutindo. Porém, a partir dos estudos que temos empreendido no Grupo de Estudos e Pesquisa em Inclusão (GEPI/UNISINOS/CNPq), podemos dizer que as pesquisas e publicações dedicadas a estudar a inclusão se vinculam ao tema de formas bastante distintas. ${ }^{2}$

Algumas pesquisas apresentam a inclusão escolar como a grande metáfora da solidariedade, da evolução humana, trazendo o discurso da aceitação, da tolerância e da benevolência como central na discussão. Receber um aluno com deficiência ou com necessidades educacionais especiais na sala de aula traria a todos a oportunidade de tornarem-se hoje pessoas melhores do que eram ontem. A socialização estaria na base dos processos inclusivos vinculados a esse princípio. O simples fato de o aluno frequentar a escola, tendo a oportunidade de conviver com os demais colegas e professores, justificaria sua permanência em sala de aula. Negligencia-se a construção do conhecimento em prol da socialização do sujeito.

Outro grupo de pesquisas compreende que os processos inclusivos na escola não se justificam simplesmente em função da socialização dos sujeitos. Conviver com os demais é fundamental, mas, a participação dos alunos em sala de aula deve buscar a aprendizagem, pois a escola tem um compromisso com o desenvolvimento dos sujeitos. Nos processos inclusivos vinculados a esses princípios, reside uma grande preocupação com a construção de materiais e a implementação de metodologias de ensino que venham a produzir uma aprendizagem individualizada, levando em consideração as necessidades específicas dos sujeitos, suas potencialidades e desafios. Porém, grande parte das discussões realizadas são centradas nas metodologias de ensino. A inclusão é tomada como algo natural, como se ela estivesse, desde sempre, aí no mundo.

E, por fim, outro grupo de pesquisas procura problematizar a inclusão escolar que se naturaliza como um imperativo nos sistemas educacionais, buscando compreendê-la como mobilizadora de processos de in/exclusão, uma vez que tensões permanentes estão em jogo. As pesquisas realizadas no GEPI vinculam-se a este último grupo, por entender que a inclusão não pode ser vista como um lugar de chegada, como um bloco homogêneo de ações que, se colocadas em prática, garantirão a inclusão nas escolas.

Em primeiro lugar, é importante considerarmos o fato de que não existe a "escola inclusiva", o que existe são processos de in/exclusão permanentes vivenciados por todos os sujeitos envolvidos no processo educativo. Devemos levar em consideração, em nossa análise, o fato de que a instituição escolar foi pensada e constituída como um espaço de práticas homogeneizantes - espaço em que a diferença incomoda, atrapalha, desestabiliza. 
Assim, sempre que o sujeito se desvia, mesmo que por alguns instantes, do ideal de normalidade que pauta as relações escolares, ele vivencia processos de exclusão. Como exemplo, podemos citar: um jogo de futebol em que determinado aluno demonstra não ter a mesma habilidade dos demais para realizar as jogadas ensaiadas pelo grupo; uma atividade oral, em sala de aula, em que o aluno "engasga" e não consegue responder ao questionamento do professor; uma brincadeira, na pracinha da escola, em que uma das meninas briga com as demais porque gostaria de brincar de forma diferente daquela sugerida pelas colegas. Enfim, os exemplos seriam infinitos e demonstram que todos nós podemos estar, mais ou menos, "incluídos" a qualquer momento, não somente no espaço escolar, mas também nos diferentes espaços sociais, nos quais nos movimentamos.

Desse modo, podemos pensar que os processos de in/exclusão fazem parte da nossa vida social e do sistema educativo. Não há como evitar a ambivalência presente nas relações sociais e de aprendizagem que vivenciamos diariamente. O que cabe à Pedagogia, nesse caso, é partir desses processos de in/exclusão para criar e organizar estratégias que percebam as questões individuais e de grupo, que permeiam o processo de aprendizagem, e utilizá-las a seu favor, seja como pistas para estudo e pesquisa, seja como produção de práticas pedagógicas que tensionem permanentemente os processos de ensino e aprendizagem implementados em sala de aula.

Porém, o que se constitui em uma grande preocupação, na escola, para quem se dedica a refletir filosoficamente acerca dos processos de in/exclusão buscando qualificar a prática pedagógica, é o que Veiga-Neto (2001) chama de "inclusão excludente". Todos são chamados a ocupar o espaço da escola, no entanto, dentro desse espaço, muitos são produzidos como anormais, a partir de diagnósticos clínicos que dizem sempre da impossibilidade, da falta, da dificuldade, do não-saber desses sujeitos. Castel (2008, p. 13-14) diz que

É neste sentido que podemos falar de discriminação negativa. Não se trata de um pleonasmo. Existem formas de discriminação positivas que consistem em fazer mais por aqueles que têm menos. [...] Mas, a discriminação negativa não consiste somente em dar mais àquele que tem menos; ela, ao contrário, marca seu portador com um defeito quase indelével. Ser discriminado negativamente significa ser associado a um destino embasado numa característica que não se escolhe, mas que os outros no-la devolvem como uma espécie de estigma. A discriminação negativa é a instrumentalização da alteridade, constituída em favor da exclusão.

Preocupações a respeito de situações vinculadas a essa questão fazem parte do que mobilizou as pesquisas que apresentamos a seguir. Procuramos mostrar o quanto os processos de in/exclusão na escola têm sido marcados pela "inclusão excludente" ou pela "discriminação negativa", como melhor nos convier chamar. 


\section{Problematizando os processos inclusivos na escola}

Retomando as questões mobilizadoras da escrita deste artigo, queremos direcionar a discussão para uma questão que tem nos preocupado, no que se refere aos sentidos e práticas de inclusão instituídos no interior da escola e/ou em outros espaços educativos. Muitas são as questões que poderíamos discutir, mas, em especial, nos limites deste artigo, queremos problematizar o que percebemos como certo silenciamento dos saberes pedagógicos nos processos inclusivos. Para explicar melhor de que forma enxergamos esse apagamento da Pedagogia nas práticas escolares inclusivas, faremos um pequeno inventário de algumas produções do GEPI que apontam essa questão como uma problemática a ser investigada³.

No texto de Arnold (2007), Dificuldade de aprendizagem em tempo de escola para todos, a autora problematiza o quanto o encaminhamento de alunos a serviços de apoio pedagógico tem proliferado nas escolas. Segundo Arnold, diversos especialistas (da área médica e da área psi), legitimados pela Pedagogia, produzem o sujeito não-aprendente "como aquele que se encontra em um estado permanente de corrigibilidade" (p. 105).

No artigo intitulado Alunos não-aprendentes, Silveira (2007) discute as representações construídas sobre os alunos posicionados como não-aprendentes e percebe que muitos pareceres descritivos redigidos pelos professores ao encaminharem seus alunos para serviços de apoio pedagógico "apontam a indisciplina como o motivo para a não-aprendizagem dos alunos" (p. 119). Sobre esses alunos, incidem processos de normalização, buscando-se sua correção para que consigam encaixar-se em um padrão de normalidade. Mais uma vez, apaga-se aí o saber da Pedagogia, que apenas justifica a não-aprendizagem dos sujeitos a partir do disciplinamento do corpo, e não do disciplinamento dos saberes.

Menezes (2008), no texto Inclusão: entre pedagogias, espaços e saberes, problematiza os sentidos da escola inclusiva e sua aparente "simplicidade", mostrando o quão complexas são as relações e aprendizagens que se estabelecem no espaço da sala de aula. Em sua análise, traz à tona a discussão sobre o papel dos especialistas:

Em épocas de escola inclusiva, há que existir aqueles que, por possuírem saberes específicos sobre os alunos incluídos, são autorizados a falar por eles. Tais saberes não estão ao alcance de "qualquer um", e sim de especialistas. Estes são os profissionais que podem dizer o que, como e por que trabalhar com o aluno que não aprende. Na verdade, a emergência dos especialistas constitui-se como uma das condições de possibilidade para a existência da escola inclusiva, e, nesse sentido, é à espera desses experts $^{4}$ que as escolas estão. (MENEZES, 2008, p. 128-129)

No artigo intitulado A invenção dos alunos na escola, Lopes (2008) problematiza a produção indefinida de diagnósticos acerca dos alunos; estes são produzidos a partir de saberes clínicos que justificam a sua posição de não-aprendizagem. Ao analisar a proliferação de diagnósticos de TDAH, a autora desafia-nos a pensar o quanto a Pedagogia utiliza os saberes da área médica e da área psi para justificar os limites da aprendizagem desses sujeitos, tirando o foco das ações que competem à Pedagogia:

Revista Educação Especial | v. 27 | n. 49 | p. 327-340| maio/ago. 2014

Santa Maria 
Quando a resistência dos alunos aos processos de homogeneização se manifesta, muitos mecanismos de dominação e docilização são acionados; entre eles, os serviços de apoio pedagógico, as clínicas de psicopedagogia e de educação especial e as clínicas integradas por neurologistas, psicólogos e terapeutas de diferentes tipos. Depois de os alunos serem considerados problemas serem encaminhados para diferentes especialistas - os quais, muitas vezes, atestam hiperatividade, déficit de atenção, dislexia, etc. -, a escola ganha elementos para afirmar que estão no indivíduo e não no sistema escolar os problemas para que a não-aprendizagem aconteça. (LOPES, 2008, p. 67)

O texto escrito por Lockmann e Traversini (2011), Saberes morais, psicológicos, médicos e pedagógicos e seus efeitos na inclusão escolar, aponta o quanto as ciências psi têm operado na escola, mostrando-se eficientes no governamento dos sujeitos, desvendando a subjetividade infantil e produzindo uma autotransformação de si. Já, o saber médico ocupa seu espaço ao descrever, classificar, diagnosticar e tratar os sujeitos anormais. A partir dos rótulos criados pelos diagnósticos, a Pedagogia, mais uma vez, silencia naquela tarefa que seria sua: pensar, criar e inventar novas formas de ensinar e de aprender.

No artigo Escola contemporânea: um espaço de convivência, Fabris (2007) discute o quanto a escola contemporânea tem priorizado a socialização dos indivíduos nos processos de in/exclusão escolar, em detrimento do conhecimento propriamente dito. Desse modo, é possível dizer que o saber pedagógico sofre uma espécie de apagamento no contexto escolar.

Essas são algumas discussões produzidas a partir de pesquisas realizadas na área da Educação que demonstram preocupação com o apagamento da Pedagogia na construção de processos inclusivos. Na seção seguinte, procuramos mostrar a relação entre os saberes da educação, saúde e Pedagogia e os conhecimentos da área psi, na produção dos sujeitos ditos e considerados anormais, a partir de uma norma previamente estabelecida.

\section{Relações entre educação, saúde, Pedagogia e os saberes da área psi}

As discussões apresentadas até o presente momento demonstram que os processos de inclusão escolar estão envolvidos na produção da (a)normalidade. O diagnóstico passa a ser visto como uma verdade absoluta sobre o sujeito, de modo que as intervenções, muitas vezes, são restritas à medicalização. Psicologia, Neurologia, Psiquiatria e Fonoaudiologia, dentre outras áreas de conhecimento, são acionadas no sentido de "falarem sobre o sujeito" e "darem conta da sua situação" - medicalização da anormalidade.

Porém, é importante perguntarmos: e o saber pedagógico? Que lugar ele ocupa nos processos de inclusão escolar? Que intervenções pedagógicas são pensadas no interior da escola? Que possibilidades de ensino e de aprendizagem são colocadas em circulação? Como os sujeitos deficientes incluídos na escola têm acesso ao conhecimento propriamente dito? 
Acreditamos que essas questões devam ser debatidas no interior da escola, bem como em outros espaços educativos, uma vez que os processos de in/exclusão não se restringem - e acreditamos que não devam se restringir - à socialização do sujeito. É preciso mais, o acesso ao conhecimento é fundamental. E é, justamente, nesse sentido que o saber pedagógico tem uma contribuição essencial. Mas por que tal saber é sobrepujado pelos saberes da área médica?

Para compreendermos melhor essa questão, é fundamental retomarmos, mesmo que brevemente, a relação entre saberes médicos, saberes da área psi e saberes pedagógicos. Para tal, é importante recorrermos à etimologia da palavra pedagogia, que significa paidós (criança) e agodé (condução), ou seja, a Pedagogia é a ciência responsável pela condução das crianças, sendo que as formas de condução mudam ao longo do tempo e do espaço. Como diz Ghiraldelli (2007, p. 11), na Grécia Antiga, "o pedagogo era apenas um guia para a criança

[...] ele tinha como função colocá-la no caminho da escola e, metaforicamente, na direção do saber"; hoje o pedagogo é "o que lida com os meios intelectuais e técnicos que possibilitam o ensino e a aprendizagem de modo ótimo". (p. 12)

Pode-se dizer que a Pedagogia, tal qual a conhecemos, ou seja, como ciência que trata dos meios intelectuais e técnicos que viabilizam o ensino e a aprendizagem de modo ótimo -, se constituiu ao longo da Modernidade, do século XVI em diante. Esse período caracterizou-se pela busca da ordem em todas as coisas, sendo que a rotinização do tempo e o quadriculamento do espaço foram essenciais nessa lógica. A normatização - produção de normas - e a normalização - a submissão dos sujeitos aos processos de enquadramento nas normas - produziram a naturalização ${ }^{5}$ de condutas desejáveis e de condutas indesejáveis. É importante ressaltar que as instituições modernas (escola, família, fábrica, hospital, prisão) tiveram um papel essencial nos processos de ordenação social.

Ao mesmo tempo em que são criadas as instituições - responsáveis, em um primeiro momento, pela correção dos indivíduos -, a infância é inventada. A criança, que durante a Idade Média era considerada um miniadulto, passa a ser objeto de estudo das mais variadas áreas de conhecimento, e a infância transforma-se, no decorrer da Modernidade, em uma época especial na vida dos sujeitos. Para melhor compreender, classificar, comparar e observar as crianças, era fundamental que elas frequentassem a instituição escolar.

Ramos do Ó (2008) diz que as primeiras escolas populares europeias foram criadas nos séculos XVI e XVII pela Igreja e serviram de instrumentos de aprofundamento e intensificação da direção pastoral das consciências. A emergência da civilização escolar estará sob a tutela da Igreja até meados do século XVIII, quando as pedagogias disciplinares se generalizam. Varela (2002) aponta que a escola coloca em circulação três modelos pedagógicos: as pedagogias disciplinares, as pedagogias corretivase as pedagogias psicológicas, porém, não há uma sucessão de um modelo para outro nessa ordem. Trata-se de uma questão de ênfases, que se acentua em determinados períodos a partir do cenário histórico mais amplo. A emergência das pedagogias psicoló- 
gicas, por exemplo, não implica a extinção das pedagogias corretivas e/ou das pedagogias disciplinares. As pedagogias disciplinares terão um papel fundamental: na regulamentação do todo social (a disciplina atuará no nível do detalhe); na mudança de percepção e organização do espaço e do tempo; na interiorização desse espaço e tempo escolares por parte dos colegiais; na organização de um campo de saber, e na construção de uma forma de subjetividade nova, o indivíduo (VARELA, 2002).

A arquitetura disciplinar do espaço será fundamental durante os séculos XVI e XVII, quando se dará todo o processo de regulamentação da economia, de regulação das circulações e de regulação das condutas. O poder disciplinar pode suprimir as penalizações e os castigos físicos, uma vez que as correções se destinam a repetir os exercícios, repetir as atividades, fazer novamente a mesma coisa (VARELA, 2002). Já, no que concerne à emergência da escola obrigatória no século XIX, ela implicará a integração das crianças das classes populares no sistema escolar de ensino. Será preciso produzir várias técnicas de domesticação desses pequenos selvagens. Membros da chamada Escola Nova colocarão em ação novos métodos e técnicas, o que implicará a reutilização do espaço e do tempo, uma nova visão da infância e a produção de outras formas de subjetividade, que serão inseparáveis de um novo estatuto de saber (VARELA, 2002). E, nesse contexto - princípios do século XX - que surgem as pedagogias corretivas, relacionadas com a Escola Nova e com a invenção da infância "anormal".

No Manifesto dos Pioneiros da Educação Nova, de 1932, documento que se tornou um clássico da pedagogia brasileira, foram incorporados princípios da pedagogia durkheiminiana - filosofia da educação que fixa objetivos educacionais difíceis de alcançar com base nos valores, papel da utopia - e da pedagogia deweyana - o conceito de pedagogia tangencia o conceito de ciências da educação, com uso de uma metodologia científica e, dando importância as políticas educacionais (GHIRALDELLI JÚNIOR, 2007).

Os novos pedagogos que aceitam as teorias pedagógicas de Rousseau, situam a criança no centro da ação educativa e acreditam que a aprendizagem deve ocorrer a partir da ação (VARELA, 2002). A atenta observação da criança, a importância da experiência no processo de aprendizagem, a noção do erro construtivo e a importância de o mestre ser um aprendiz - "em Rousseau, o educador perde o seu lugar cativo de ensinante" (STRECK, 2004, p. 86) - são questões fundamentais no pensamento desse filósofo. Sua obra traz inúmeras lições para a moderna psicologia do desenvolvimento humano, como é o caso, por exemplo, dos estágios, estudados por Piaget, da zona de desenvolvimento proximal, estudada por Vigotsky, e das fases, estudadas por Freud e Erikson (STRECK, 2004).

Pode-se dizer que, na Contemporaneidade, a educação segue com a função de conduzir o homem até a verdade. O próprio exercício de autoconhecimento nada mais é do que a busca que cada indivíduo faz de "descobrir" e de "desvendar" a sua "verdadeira essência". As pedagogias psicológicas, que estão em expansão na atualidade, partem da premissa de que o aluno pode liberar-se mediante um intenso e sistemático trabalho sobre si mesmo, ou seja, mediante um processo de personalização (VARELA, 2002). Inicia-se, a partir daí, toda uma discussão sobre o ritmo individual de cada 
aluno. Os conteúdos escolares perdem progressivamente o seu valor, e a máxima recai sobre a importância de "aprender a aprender", o que pode ser entendido como "aprender a escutar-se através dos outros" (VARELA, 2002, p. 102).

É interessante observar que a Pedagogia emerge no interior da noção de sequência normalizadora de desenvolvimento infantil (COUTINHO, 2008) - presente nas pedagogias disciplinares, corretivas e psicológicas -, de modo que ela se empalidece enquanto ciência e/ou filosofia da educação. Tal sequência normalizadora fica ainda mais evidente no contexto de ampliação da instituição escolar no século XIX - escola obrigatória para todos, que terá como tarefa principal a ordenação social, pressupondo um mundo limpo, organizado e homogêneo.

Conforme já comentamos anteriormente, a Psicologia terá uma tarefa essencial nesse sentido. É importante ressaltar que as dificuldades enfrentadas pela implantação das políticas que pretendem fazer a inclusão dos anormais se devem, especialmente, à própria construção moderna da normalidade (VEIGA-NETO, 2001).

Pode-se dizer que, no decorrer da Modernidade, se inventa um padrão de aluno ideal. Tal padrão é perseguido em muitas das nossas escolas até hoje. O que foge do padrão estabelecido é considerado anormal. A homogeneidade - todos se tornarem o mesmo - persiste em muitas das nossas práticas pedagógicas. Nesse sentido, a inclusão pode ser muito perversa, pois ela pressupõe a inclusão das diferenças para que os diferentes se tornem "o mesmo". Como isso, na maior parte das vezes, após "detectada alguma diferença, se estabelece um estranhamento, seguido de uma oposição por dicotomia: o mesmo não se identifica com o outro, que agora é um estranho" (VEIGA-NETO, 2001, p. 113).

Esse é o sujeito que passa a ser identificado como anormal - ocupando um lugar fora da média, do padrão estabelecido - e que acaba sendo incluído, para ser excluído em seguida. Parte-se do pressuposto de que a diferença precisa ser medicalizada, descrita, prescrita. O grande desafio é justamente o de refletirmos sobre a invasão de diagnósticos na escola, pois eles acabam por "definir as dificuldades e potencialidades dos alunos" (LOCKMANN; TRAVERSINI, 2011, p. 45).

Devido ao movimento higienista, o uso dos saberes da área médica na escola intensificou-se ainda mais no início do século XX. A saúde passou a ser considerada como um ideal universal que prevê normas, comportamentos e padrões (SANTOS, 2004).

Talvez o principal desafio para a área da Pedagogia seja justamente o fato de que grande parte dos discursos da área médica, psicológica e biológica, que estiveram envolvidos com a invenção da infância e com a produção de práticas normalizadoras, parte da ideia de que existe uma natureza humana impermeável à história. O próprio estudo das fases do desenvolvimento humano acabou por naturalizar os comportamentos esperados em cada etapa, de maneira que tudo que foge do padrão, da média estabelecida, é considerado anormal e precisa ser corrigido. 
Os diagnósticos que identificavam os alunos que deveriam frequentar a Educação Especial, bem como os diagnósticos que seguem sendo produzidos, atualmente, no interior da Escola Regular, são,

em quase sua totalidade, determinados por um saber médico sustentado por concepções organicistas e deterministas do ser humano [...] havendo pouca consideração sobre as relações históricas e contextuais que produzem a especificidade dos quadros diagnósticos. (BRIDI, 2011, p. 70-71)

Resta perguntar: de que modo a escola, ao organizar o seu trabalho com base nos diagnósticos clínicos, acaba por impulsionar a criação de outros diagnósticos sobre os sujeitos que dela fazem parte (BRIDI, 2011)?

Conforme já discutimos, no início do artigo, os diagnósticos acabam dizendo a verdade sobre os sujeitos, definindo suas potencialidades e dificuldades e explicando as causas da não-aprendizagem. A grande diferença hoje é que, com o imperativo da inclusão, muitos alunos não podem mais ser encaminhados para a Educação Especial e precisam permanecer na Escola Regular. Entretanto, passam a ser encaminhados para outros serviços de apoio, que podem ser potentes e importantes no processo de inclusão escolar, contanto que tenham o devido acompanhamento pedagógico, responsável pelos processos de ensino e aprendizagem.

A inclusão extrapola o acesso. Quando falamos em processos inclusivos, devemos pensar em acesso, permanência e aprendizagem. Não é incomum ouvirmos, hoje, relatos de que alguns casos de inclusão de pessoas com deficiência na escola regular têm se restringido à socialização dos sujeitos, sem a criação de estratégias específicas que possibilitem outras formas de ensinar e de aprender. É justamente nesse sentido que a Pedagogia, como ciência da educação composta por inúmeros saberes - disciplinar, curricular, da experiência, da ação pedagógica, da cultura profissional, da cultura geral, da tradição pedagógica (GAUTHIER; TARDIF, 2010) --, tem muito a fazer no interior da instituição escolar e de outros espaços educativos.

\section{Desafios da Pedagogia nos processos de inclusão escolar}

O pedagogo, alimentado por esses múltiplos saberes, deve exercer permanentemente seu julgamento em situação de ensino. É nesse sentido que Schön (1994) fala do docente profissional, isto é, aquele que, diante de uma situação complexa, mobiliza diversos saberes para chegar à boa decisão no bom momento. (GAUTHIER; TARDIF, 2010, p. 486)

Como o próprio título anuncia, nesta seção, discutimos alguns dos desafios da Pedagogia nos processos de inclusão escolar. Se, a Pedagogia constituiu-se no interior dos processos de regulação das condutas, que tiveram como pressuposto essencial a naturalização da natureza infantil, é, preciso discutir o que é pedagogia, então ela não bebe apenas na fonte da psicologia do desenvolvimento. Como diz Ghiraldelli Júnior (2007, p. 76):

Lembrando que a pedagogia se relaciona com a filosofia da educação e, portanto, fixa os objetivos da educação e, ela própria, traça as normas mais gerais do que se deve fazer em educação, 
cabe também mostrar como ela apresenta os meios e os procedimentos para que a educação que ela propõe se efetive. É aí que a pedagogia nutre um de seus campos técnicos mais concorridos, o campo da didática.

O mesmo autor faz uma crítica à sobrevalorização da didática no cenário brasileiro. Segundo ele, a Pedagogia é a interação entre a filosofia da educação e a didática, portanto, ela deve manter um canal aberto de conversação entre esses dois elementos necessários à educação.

Ao refletirmos sobre a educação e os processos de ensino e aprendizagem, precisamos colocar em circulação os saberes elencados anteriormente, assim como compreender o cenário político, econômico e social mais amplo, no qual a escola está inserida. Partimos do pressuposto de que, em educação, o único a priori é o histórico. Portanto, precisamos repensar constantemente as estratégias utilizadas nas práticas pedagógicas.

No que diz respeito à didática - procedimentos que possibilitam que alguém tenha acesso ao conhecimento -, o desafio é grande, pois o pedagogo deve ser alguém capaz de potencializar o ensino dos conteúdos que conhece. Porém, não é raro termos profissionais que falam sobre o ensino, mas sem conhecer aquilo que será ensinado (GHIRALDELLI JÚNIOR, 2007).

Nesse sentido, é fundamental que os pedagogos tenham uma formação sólida, discutam o currículo escolar, se apropriem daquilo que será ensinado e repensem os processos educativos a partir do conjunto de saberes que constituem a Pedagogia como ciência. O diagnóstico pode ser o ponto de partida no processo de desenvolvimento das potencialidades dos indivíduos, e não o contrário - um limitador do sujeito, apontando suas impossibilidades. Fica o desafio!

\section{Referências}

ACORSI, R. (Des)encaixes: espaço e tempo na escola contemporânea. Dissertação (Mestrado em Educação). Programa de Pós-Graduação em Educação. Universidade Luterana do Brasil, Canoas, RS, 2007.

ARNOLD, D. K. Dificuldade de aprendizagem em tempo de escola para todos. In: LOPES, M. C.; DAL'IGNA, M. C. In/exclusão: nas tramas da escola. Canoas: Ed. ULBRA, 2007.

BRIDI, F. R. de S. Processos diagnósticos e de identificação dos alunos da educação especial: implicações no contexto escolar. In THOMA, A.; HILLESHEIM, B. (Orgs.). Políticas de inclusão: gerenciando riscos e governando as diferenças. Santa Cruz do Sul: EDUNISC, 2011, p. 70-86.

CASTEL, R. A discriminação negativa: cidadãos ou autóctones? Petrópolis: Vozes, 2008.

COUTINHO, K. D. A emergência da Psicopedagogia no Brasil. 2008. Tese (Doutorado em Educação) $\mathrm{Q}$ Programa de Pós-Graduação em Educação, Faculdade de Educação, Universidade Federal do Rio Grande do Sul, Porto Alegre: UFRGS, 2008.

FABRIS, E. H. A Escola Contemporânea: um espaço de convivência?. In: 30ª Reunião anual da ANPED, 2007, Caxambu/MG. Constituição Brasileira, Direitos Humanos e Educação. Rio de Janeiro: ANPED, 2007.

GAUTHIER, C.; TARDIF, M. A Pedagogia: teorias e práticas da Antiguidade aos nossos dias. Petrópolis: Vozes, 2010.

GUEDES, B. S. Sobre surdos, bocas e mãos: saberes que constituem o currículo de fonoaudiologia. Dissertação (Mestrado em Educação). Programa de Pós-Graduação em Educação. Universidade do Vale do Rio dos Sinos, São Leopoldo, RS, 2010.

Revista Educação Especial | v. 27 | n. 49 | p. 327-340| maio/ago. 2014

Santa Maria

Disponível em: <http://www.ufsm.br/revistaeducacaoespecial> 
GHIRALDELLI JÚNIOR, P. O que é Pedagogia. São Paulo: Brasiliense, 2007.

KLEIN, R. R. A reprovação escolar como ameaça nas tramas da modernização pedagógica. Tese (Doutorado em Educação). Programa de Pós-Graduação em Educação. Universidade do Vale do Rio dos Sinos, São Leopoldo, RS, 2010.

KRAEMER, G. M. Estratégias de governamento dos sujeitos surdos na e para a inclusão escolar. Dissertação (Mestrado em Educação). Programa de Pós-Graduação em Educação. Faculdade de Educação da Universidade Federal do Rio Grande do Sul, Porto Alegre, RS, 2011.

LOCKMANN, K. Inclusão escolar: saberes que operam para governar a população. Dissertação (Mestrado em Educação). Programa de Pós-Graduação em Educação. Faculdade de Educação da Universidade Federal do Rio Grande do Sul, Porto Alegre, RS, 2010.

LOCKMANN, K; TRAVERSINI, C. S. Saberes morais, psicológicos, médicos e pedagógicos e seus efeitos na inclusão escolar. In THOMA, A.; HILLESHEIM, B. (Orgs.). Políticas de inclusão: gerenciando riscos e governando as diferenças. Santa Cruz do Sul: EDUNISC, 2011, p.35-56.

LOPES, M. C.; DAL'IGNA, M. C. (Orgs.). In/exclusão: nas tramas da escola. Canoas: Ulbra, 2007.

LOPES, M. C. Inclusão: a invenção dos alunos na escola. In: RECHICO, C. F.; FORTES, V. G. A educação e a inclusão na contemporaneidade. Boa Vista: Editora da UFRR, 2008.

MELLO, V. S. S. de. A constituição da comunidade surda no espaço da escola: fronteiras nas formas de ser surdo. Dissertação (Mestrado em Educação). Programa de Pós-Graduação em Educação. Universidade do Vale do Rio dos Sinos, São Leopoldo, RS, 2011.

MENEZES, E. da C. P. de. Inclusão: entre Pedagogias, Espaços e Saberes. In: RECHICO, C. F.; FORTES, V. G. A educação e a inclusão na contemporaneidade. Boa Vista: Editora da UFRR, 2008.

MENEZES, E. da C. P. de. A maquinaria escolar na produção de subjetividades para uma sociedade inclusiva. Tese (Doutorado em Educação). Programa de Pós-Graduação em Educação. Universidade do Vale do Rio dos Sinos, São Leopoldo, RS, 2011.

PROVIN, P. O imperativo da inclusão nas universidades comunitárias gaúchas: produzindo "atitudes de inclusão"? Dissertação (Mestrado em Educação). Programa de Pós-Graduação em Educação. Universidade do Vale do Rio dos Sinos, São Leopoldo, RS, 2011.

RAMOS DO Ó, J. A maquinaria escolar moderna entre os séculos XVI e XIX: estruturas de uma história do presente. Texto apresentado durante o curso de extensão ministrado por Ramos do Ó na Unisinos, segundo semestre de 2008.

RECH, T. L. A inclusão escolar no Governo FHC: movimentos que a tornaram uma "verdade" que permanece. Dissertação (Mestrado em Educação). Programa de Pós-Graduação em Educação. Universidade do Vale do Rio dos Sinos, São Leopoldo, RS, 2010.

SARDAGNA, H. V. Práticas normalizadoras na Educação Especial: um estudo a partir da rede municipal de ensino de Novo Hamburgo - RS (1950 a 2007). Tese (Doutorado em Educação). Programa de Pós-Graduação em Educação. Universidade do Vale do Rio dos Sinos, São Leopoldo, RS, 2008.

SANTOS, I. M. dos. Cuidar e curar para governar: as campanhas de saúde na escola. 2004. Dissertação (Mestrado em Educação) - Programa de Pós-Graduação em Educação, Faculdade de Educação, Universidade Federal do Rio Grande do Sul, Porto Alegre: UFRGS, 2004.

SCHUCK, M. "A Educação dos Surdos no RS": currículos de formação de professores de surdos. Dissertação (Mestrado em Educação). Programa de Pós-Graduação em Educação. Universidade do Vale do Rio dos Sinos, São Leopoldo, RS, 2011.

SILVEIRA, P. B. Alunos não-aprendentes. In: LOPES, M. C.; DAL'IGNA, M. C. In/exclusão: nas tramas da escola. Canoas: Ed. ULBRA, 2007.

STRECK, D. R. Rousseau \& a Educação. Belo horizonte: Autêntica, 2004.

SZULCZEWSKI, D. M. Professor ou intérprete educacional? Monografia (Licenciatura em Pedagogia). Curso de Pedagogia. Universidade do Vale do Rio dos Sinos, São Leopoldo, RS, 2010.

VARELA, J. Categorias espaço-temporais e socialização escolar: do individualismo ao narcisismo. In: COSTA, M. V. (Org.). Escola básica na virada do século: cultura, política e currículo. São Paulo: Cortez, 2002, p. $73-106$. 
VEIGA-NETO, A. Incluir para excluir. In: LAROSSA, J; SKLIAR, C. (Orgs.). Habitantes de Babel: políticas e poéticas da diferença. Belo Horizonte: Autêntica, 2001, p. 105-118.

\section{Notas}

${ }^{1}$ Em sua dissertação de Mestrado, Rech (2010), ao analisar a emergência da inclusão escolar no Brasil, percebe que esse movimento "ganhou potência política a partir do Governo FHC e continua, até hoje, a se materializar como verdade educacional" (p. 166).

${ }^{2}$ Sabemos que qualquer tipo de classificação é limitado e implica alguns riscos. Porém, nossa intenção aqui não é dizer que essas classificações são as únicas possibilidades de vinculação ao tema da inclusão, nem apontar a melhor forma de reflexão sobre os processos inclusivos. Pretendemos apenas discutir como o tema vem sendo pautado no cenário educacional.

${ }^{3}$ Além dos trabalhos aqui citados, selecionados em função de sua aderência específica ao tema que estamos discutindo nesse artigo, a quem tiver interesse pela temática da Inclusão indicamos a leitura de ACORSI (2007), GUEDES (2010), KLEIN (2010), KRAEMER (2011), LOCKMANN (2010), LOPES e DAL'IGNA (2007), MELLO (2011), MENEZES (2011), PROVIN (2011), RECH (2010), SARDAGNA (2008), SCHUCK (2011),

${ }^{4} \mathrm{O}$ curioso é que os especialistas autorizados a falar sobre inclusão geralmente são da área médica, da área psi questão que será discutida na própria seção.

${ }^{5}$ Quando nos referimos à naturalização, queremos dizer que esses processos não estiveram desde sempre aí no mundo. Os padrões de conduta são produções históricas datadas que, portanto, podem ser modificadas.

\section{Correspondência}

Morgana Domênica Hattge - Centro Universitário Univates, Curso de Pedagogia. Av. Avelino Tallini, 171, Universitário, CEP: 95900-000 - Lajeado, Rio Grande do Sul - Brasil.

E-mail:morganahdomenica@yahoo.com.br

Recebido em 21 de janeiro de 2013

Aprovado em 03 de abril de 2013 